\title{
The level of concern for oral health in children visiting the Dental Hospital of Hasanuddin University
}

Tingkat kepedulian terhadap kesehatan gigi dan mulut pada anak yang berkunjung ke
Rumah Sakit Gigi dan Mulut Universitas Hasanuddin

\author{
${ }^{1}$ Sherly Horax, ${ }^{2}$ Eri Hendra Jubhari, ${ }^{3}$ Aldy Anzhari Ayub \\ ${ }^{1}$ Department of Pediatric Dentistry \\ ${ }^{2}$ Department of Prosthodontics \\ ${ }^{3}$ Dental Student \\ Fakultas Kedokteran Gigi, Universitas Hasanuddin \\ Makassar, Indonesia \\ Correspondence author: Sherly Horax, e-mail: sherly.unhas@gmail.com
}

\begin{abstract}
Background:The visit of children to the dentist to have their teeth checked is not routinely done. There is stilla lack of awareness or concern for children about dental health due to a lack of knowledge about preventive and dental care in children to get optimal oral health. Aim: To determine the relationship between the level of motivation, cooperation and knowledge about oral dental health on oral health. Methods: Analytical observational research and cross sectional study approach was carried out in September 2016 at the Dental Clinic for Children, Dental Hospital of Hasanuddin University. With the accidental sampling technique, all children aged 6-17 years who visited the clinic filled out a questionnaire and performed an oral status check. Results: The Kruskall wallis test showed that there was a significantrelationship between the level of motivation and knowledge of children on oral health and the level of visits and high levels of cooperation was dominated by patients who were picked up by the operator. Conclusion: There is a relationship between the level of motivation and knowledge about children's oral health and the highest level of cooperation is dominated by patients who are picked up by the operator.
\end{abstract}

Key words: motivation, cooperation, knowledge, oral health, visits, dental hospital

\begin{abstract}
ABSTRAK
Latar belakang: Kunjungan anak ke dokter gigi untuk memeriksa giginya belumrutin dilakukan. Masih kurangnya kesadaran ataupun kepedulian anak terhadap kesehatan gigi akibat kurangnya pengetahuan mengenai hal preventif dan perawatan gigi pada anakuntuk mendapatkan kesehatan mulut yang optimal.Tujuan:Untuk mengetahuihubungantingkat motivasi, kooperatif dan pengetahuan tentang kesehatan gigi mulut terhadap kesehatan gigi dan mulut. Metode: Penelitian observasi analitik dan pendekatan cross sectional study dilaksanakan padabulan September 2016 di Klinik Ilmu Kedokteran Gigi Anak Rumah Sakit Gigi dan Mulut Universitas Hasanuddin(IKGA RSGMUnhas). Denganteknik accidental sampling seluruh anak berusia 6-17 tahun yang berkunjung ke Klinik yang mengisi kuesioner dan melakukan pemeriksaan status oral. Hasil: Uji Kruskall wallis menunjukkan bahwa ada hubungan tingkat motivasi dan pengetahuan anak yang signifikan terhadap kesehatan gigi dan mulutnya dan tingkat kunjungan dan tingkat kooperatif tinggi didominasi oleh pasien yang dijemput oleh operator. Simpulan: Ada hubungan antara tingkat motivasi dan pengetahuan terhadap kesehatan gigi dan mulut anak dan tingkat kooperatif tertinggi didominasi oleh pasien yang dijemput oleh operator

Kata kunci: motivasi, kooperatif, pengetahuan, kesehatan gigi dan mulut, kunjungan, rumah sakit gigi dan mulut Received: 30 April 2020

Accepted: 1 June 2020

Published: 1 August 2020

\section{PENDAHULUAN}

Sampai saat ini, anak hanya mengunjungi klinik gigi bila ada kelainan di rongga mulutnya.Kunjungan yang bersifat preventif masih belum rutin dilakukan. Begitupunorang tua belum terlalu mengetahui tentang hal seputar kesehatan gigi. Bahkan, beberapa diantaranya membiarkan gigi sulung rusak karena memiliki prinsip bahwa gigi sulung merupakan gigi sementara yang nantinya akan digantikan dengan yang baru.

Menurut rekomendasi The American Academy of Pediatric Dentistry (AAPD) dan American Dental Association (ADA), seorang anak harus mulai melakukan kunjugan ke dokter gigi setelah gigi sulung pertamanyaerupsi dan tidak boleh lebih dari usia 12 bulan. ${ }^{1}$

Rekomendasiini ditujukanuntuk mendeteksi dan mengontrol berbagai penyakit gigi, terutama karies gigi yang merupakan penyakit mulut yang paling sering pada anak dan dapat terjadi segera setelah gigi erupsi. ${ }^{1}$ Selain itu, rekomendasi ini juga didasarkan pada penetapan dasarpendidikan dari beberapa penelitian akhirini,masih kurangnyakesadaran anak ataupun kepedulian anak terhadap kesehatan gigi akibat kurangnya pengetahuan mengenai pencegahandan perawatan gigi pada anak untuk mendapatkan kesehatan mulut yang optimal pada masa kanak-kanak hingga dewasa. ${ }^{2-4}$

Kebersihan gigi dan mulutjuga merupakan sebagian dari kesehatan tubuh yang tidak terpisahkan dari kesehatan tubuh yang lain, sebab kebersihan gigi dan
\end{abstract}


mulut dapat mempengaruhi kesehatan seluruh tubuh. ${ }^{5}$ Pemeliharaan kebersihan gigi dan mulut merupakan salah satu upaya meningkatkan kesehatan karena dapat mencegah terjadinya penyakit di rongga mulut. ${ }^{6} \mathrm{Ke}-$ sehatan gigi dan mulut merupakan salah satu aspek pendukung paradigma sehat dan strategi pembangunan nasional untuk mewujudkan Indonesia sehat. ${ }^{7}$

Dari uraian tersebut, peneliti ingin mengetahui tingkat kepedulian anakterhadapkesehatan giginya dengan mengetahui motivasi anak untuk berkunjung ke Rumah Sakit Gigi dan Mulut Universitas Hasanuddin (RSGM Unhas) dan mengetahui tingkat kooperatif dan pengetahuan anak mengenai kesehatan gigi dan mulut sehingga perlu diketahui hubungan tingkat motivasi anak untuk berkunjung, tingkat kooperatif dan tingkat pengetahuan anak terhadap kesehatan gigi dan mulut, serta mengetahui kondisi status oral anak yang berkunjungke Klinik AnakRSGMUnhas Hasanuddin.

\section{METODE}

Penelitian observasional analitik dengan pendekatan cross sectional study dilaksanakan pada bulan September 2016 di Klinik Anak RSGM Unhas. Dengan cara accidental sampling, seluruh anak berusia 617 tahun yang berkunjung diberi kuesioner mengenai motivasi,tingkat kooperatif, dan tingkat pengetahuan kesehatan gigi dan mulut. Kategori penilaian dibagi 3 , yaitu baik, sedang, dan rendah. Selanjutnya status oral diperiksa menggunakan indeks oral hygiene simplified dengan menjumlahkan debris index simplified (DI-S) dan calculus index simplified (CI-S). Data yang diperoleh diolah dengan menggunakan program SPSS versi 20 , dan disajikan dalam bentuk tabel distribusi frekuensi.

\section{HASIL}

Dari pengisian kuesioner dan pemeriksaan status oral diperoleh data pada tabel-tabel berikut.

Tabel 1 Distribusi responden berdasarkan kategori ohis pada tingkat kepedulian anak yang berkunjung ke RSGM Unhas terhadap kesehatan gigi dan mulut

\begin{tabular}{lll}
\hline Kategori OHIS & $\mathbf{n}$ & \% \\
\hline Baik & 24 & 47,0 \\
Sedang & 26 & 51,0 \\
Buruk & 1 & 2,0 \\
\hline Total & $\mathbf{5 1}$ & $\mathbf{1 0 0 , 0}$ \\
\hline
\end{tabular}

Sumber: data primer

Tabel 1 menunjukkan bahwa dari 51 responden, jumlah responden tertinggi adalah kategori OHIS sedang, yaitu sebanyak 26 orang, sedangkan kategori OHIS buruk, 1 orang. Tabel 2 menunjukkan jumlah responden tertinggi adalah kategori motivasi tinggi, yaitu sebanyak 38 orang. Sedangkan kategori motivasi sedang, 13 orang.
Tabel 2Distribusi responden berdasarkan kategori motivasi pada tingkat kepedulian anak yang berkunjung ke RSGM Unhas terhadap kesehatan gigi dan mulut

\begin{tabular}{lll}
\hline Kategori Motivasi & $\mathbf{n}$ & $\mathbf{\%}$ \\
\hline Rendah & 0 & 0 \\
Sedang & 13 & 25,5 \\
Tinggi & 38 & 74,5 \\
\hline Total & $\mathbf{5 1}$ & $\mathbf{1 0 0 , 0}$ \\
\hline
\end{tabular}

Sumber: data primer

Tabel 3 Distribusi responden berdasarkan kategori kooperatif pada tingkat kepedulian anak yang berkunjung ke RSGM Unhas terhadap kesehatan gigi dan mulut

\begin{tabular}{lll}
\hline Kategori Kooperatif & $\mathbf{n}$ & $\mathbf{\%}$ \\
\hline Rendah & 0 & 0 \\
Sedang & 2 & 3,9 \\
Tinggi & 49 & 96,1 \\
\hline Total & $\mathbf{5 1}$ & $\mathbf{1 0 0 , 0}$ \\
\hline
\end{tabular}

Sumber: data primer

Pada kategori kooperatif (Tabel 3), tinggi sebanyak 49 orang dan sedang sebanyak 2 orang $(96,10 \%)$. Sedangkan Tabel 4 menunjukkan bahwa jumlah kategori pengetahuan tinggi, yaitu 45 orang dan kategori pengetahuan sedang, yaitu 6 orang $(11,8 \%)$.

Tabel 4 Distribusi responden berdasarkan kategori pengetahuan pada tingkat kepedulian anak yang berkunjung ke RSGM Unhas terhadap kesehatan gigi dan mulut

\begin{tabular}{lll}
\hline Kategori Pengetahuan & $\mathbf{N}$ & \% \\
\hline Rendah & 0 & 0 \\
Sedang & 6 & 11,8 \\
Tinggi & 45 & 88,2 \\
\hline Total & $\mathbf{5 1}$ & $\mathbf{1 0 0 , 0}$ \\
\hline
\end{tabular}

Sumber: data primer

Tabel 5 Distribusi responden berdasarkan kategori kunjungan pada tingkat kepedulian anak yang berkunjung ke RSGM Unhas terhadap kesehatan gigi dan mulut

\begin{tabular}{lll}
\hline Kategori Kunjungan & $\mathbf{N}$ & $\mathbf{\%}$ \\
\hline Datang Sendiri & 8 & 15,7 \\
Diantar Orang tua & 10 & 19,6 \\
Diantar Wali & 5 & 9,8 \\
Dijemput & 28 & 54,9 \\
\hline Total & $\mathbf{5 1}$ & $\mathbf{1 0 0 , 0}$ \\
\hline Sumber: data primer & &
\end{tabular}

Tabel 6 Hubungan antara pengetahuan, tingkat kooperatif, dan motivasi anak yang berkunjung ke RSGM Unhas terhadap kesehatan rongga mulutnya

\begin{tabular}{lcc}
\hline Variabel & Mean \pm SD & $\begin{array}{c}\text { Comparative } \\
\text { Test }(\boldsymbol{p} \text {-value })\end{array}$ \\
\hline Pengetahuan & $39,14 \pm 3,504$ & $0,048^{*}$ \\
Tingkat Kooperatif & $39,76 \pm 2,346$ & 0,978 \\
Motivasi & $36,10 \pm 3,545$ & $0,011^{*}$ \\
* Kruskall wallis test: $\mathrm{p}<0,05 ;$ significant &
\end{tabular}

Terlihat pada Tabel 5, bahwa jumlah responden tertinggi adalah pada kategori kunjungan yang dijem- 
put, yaitu 28 orang. Sedangkanjumlah terendah adalah pada kategori diantar wali, yaitu 5 orang.

Pada tabel6tampakbahwanilai reratapengetahuan yakni 39,14 dengan SD 3,504. Nilai rerata tingkat kooperatif yakni 39,76 dengan SD 2,346. Sedangkan nilaireratamotivasi yakni 36,10 dengan SD 3,545. Uji Kruskall wallis menunjuk nilai-p berturut-turut 0,048 , 0,978 dan $0,011(\mathrm{p}<0,05)$ yang berarti ada hubungan yang signifikan antara pengetahuan dan motivasi anak yang berkunjung ke RSGMUnhas terhadapkesehatan rongga mulutnya, sedangkan pada tingkat kooperatif tidak terdapat hubungan yang signifikan.

Nilai reratapengetahuan yakni 39,14 dengan SD 3,504 , nilai rerata tingkat kooperatif yakni 39,76 dengan SD 2,346, nilai rerata motivasi yakni 36,10 dengan SD 3,545, sedangkan nilai rerata OHIS 1,316 denganSD0,4320 (Tabel7). Uji Kruskall wallis menunjukkan nilai-p berturut-turut $0,327,0,039,0,318$ dan $0,794(p<0,05)$ yang berarti signifikan. Hal ini berarti ada perbedaan tingkat kooperatif pada anak yang datang sendiri, diantar orang tua, diantar wali, dan yang dijemput; berbeda dengan pengetahuan, tingkat motivasi serta kesehatan gigi dan mulut.

Tabel 7 Perbedaan Tingkat Motivasi, Tingkat Kooperatif, pengetahuan serta Kesehatan Gigi dan Mulut kunjungan Anak RSGM Kandea Unhas

\begin{tabular}{llc}
\hline Variabel & Mean \pm SD & $\begin{array}{c}\text { Comparative } \\
\text { Test }(\boldsymbol{p} \text {-value })\end{array}$ \\
\hline Pengetahuan & $39,14 \pm 3,504$ & 0,327 \\
Tingkat Kooperatif & $39,76 \pm 2,346$ & $0,039 *$ \\
Motivasi & $36,10 \pm 3,545$ & 0,318 \\
Kategori OHIS & $1,316 \pm 0,4320$ & 0,794 \\
\hline * Kruskall wallis test: $p<0.05 ;$ significant &
\end{tabular}

*Kruskall wallis test: $p<0.05$; significant

Tab8 Perbandingan tingkat kooperatif anak yang berkunjung ke RSGM Kandea Unhas terhadap kesehatan rongga mulutnya

\begin{tabular}{lcccc}
\hline \multirow{2}{*}{$\begin{array}{l}\text { Tingkat } \\
\text { Kooperatif }\end{array}$} & \multicolumn{4}{c}{ Kunjungan } \\
\cline { 2 - 5 } & $\begin{array}{l}\text { Datang } \\
\text { sendiri }\end{array}$ & $\begin{array}{l}\text { Diantar } \\
\text { Orang tua }\end{array}$ & $\begin{array}{l}\text { Diantar } \\
\text { Wali }\end{array}$ & Dijemput \\
\hline Rendah & 0 & 0 & 0 & 0 \\
Sedang & 0 & 2 & 0 & 0 \\
Tinggi & 8 & 8 & 5 & 28 \\
\hline
\end{tabular}

Tabel 8 menunjukkan perbandingan tingkat kooperatif anak yang datang sendiri, diantar orang tua, diantar wali dan yang dijemput; tampak bahwa tingkatkooperatifanakyang dijemput, tinggi dan tidakada yang rendah. Sedangkan tingkat kooperatif sedang ditemukan pada anak yang diantar oleh orang tua ke RSGM Unhas.

\section{PEMBAHASAN}

Pada tabel 1 tampak bahwa kebersihan gigi dan mulut anak yang berkunjung ke RSGM Unhas masih cukup baik. Menurut Ramadhan, salah satu hal yang mempengaruhi kebersihan mulut yaitu pengetahuan mengenai kesehatan gigi dan mulut. ${ }^{14}$ Dapat dilihat pada tabel 6 mengenaitingkat pengetahuan bahwa pasien yang berkunjung ke RSGM Unhas rata-rata memiliki tingkat pengetahuan yang tinggi, sehingga kebersihan gigi dan mulut pasien menjadi lebih terjaga.

Pada tingkat motivasi anak untuk berkunjung ke RSGM Unhas masih cukup baik, seperti pada tabel 2 bahwapada tingkatan motivasi yang memiliki jumlah tertinggi ialah kategori motivasi tinggi. Pada tingkat motivasi, dapat dilihat dari kuesioner yang diberikan masih ada beberapa diantara pasien yang berkunjung karena unsur paksaan dan ingin mendapatkan imbalan dari operator. Selain itujuga terlihat masih banyak pasien yang datang karena ingin perawatan gratis untuk melakukan perawatan di RSGM Unhas; mungkin diperlukan peningkatan kualitas untuk meningkatkan kepuasan pasien di RSGM Unhas.

Dari tabel 4, tingkat pengetahuan anak yang berkunjung termasuk cukup tinggi. Banyak pasien anak yang berkunjung ke RSGM Unhas bukanlah kunjungan yang pertama, sehingga telah diberikan dental heath education (DHE) sebelumnya oleh operator.

Tingkat kooperatif anak yang berkunjung dapat dlihat dari tabel 3 bahwa jumlah responden tertinggi adalah pada kategori kooperatif tinggi. Tingkat kooperatif anak yang berkunjung termasuk tinggi. Tingkat kooperatif berdasarkan kunjungan, yang paling dominan adalah anak yang dijemput oleh operator. Hal ini sesuai dengan penelitian Syam, yang menjelaskan bahwa kunjungan pertama bagi pasien anak di RSGM bukanlah pertemuan pertama bagi pasien anak dengan operator sebagai mahasiswa kepaniteraan melainkan sudahterjadi interaksi awal antara pasien anak dengan operator karena operator membawa sendiri pasien anak tersebut. Tipe pasien anak yang dibawa oleh operator yaitu keluarga operator sendiri, anak di panti asuhan yang dijemput, anak jalanan yang sudah dibujukolehoperatoruntuk dilakukan perawatan diRSGM. Selain itu,pemilihan pasien sesuai dengan kasus yang dibutuhkan olehoperator sehingga sudah terjadi pemeriksaan klinis rongga mulut secara dini. ${ }^{15} \mathrm{Hal}$ ini sesuai dengan hasil penelitian Kent dan Blinkhorn tentang tingkahlaku pasien anak di praktikdokter gigi,yaitu bahwa anak yang berkunjung tidak teratur dan menerima prosedur perawatan selama waktu tertentu menunjukkan peningkatan kecemasan, sedangkan tingkat kecemasan bagi mereka yang berkunjung secara teratur dan mengalami beberapa prosedur perawatan invasif tidaklah berubah. Namun, anak-anak yang tidak pernahmenerima perawatan invasif, baik mereka berkunjung secara teratur atau tidak, menunjukkan kecemasan paling tinggi. ${ }^{16}$ 
Kunjungan pasien anak ke RSGM Unhas didominasi oleh pasien yang dijemput oleh operator. Tabel 5 menunjukkan bahwa masih banyak pasien yang berkunjung karena dijemput oleh operator. Hal ini menunjukkan masih kurangnya kesadaran masyarakat mengenai pentingnyakunjungan ke RSGM untuk melakukan perawatan atau hal yang bersifat pencegahan terhadap risiko terjadinya masalah kesehatan gigi dan mulut.

Pada tabel 6 tampak bahwa hasil uji Kruskall wallis bahwa ada hubungan yang signifikan antara pengetahuan dan motivasi anak yang berkunjung ke RSGM Unhas terhadap kesehatan rongga mulutnya. Sedangkan untuk tingkat kooperatif tidak terdapat hubungan yang signifikan yang mungkin disebabkan hal yang mempengaruhinya ialah kunjungan anak yang berkunjung ke RSGM Unhas. Tingkat pengetahuan dan tingkat motivasi mempengaruhi kesehatan gigi dan mulut disebabkan pengetahuan merupakan salah satu faktor yang mempengaruhi kebersihan gigi dan mulut. Tingkat motivasi anak yang berkunjung juga mempengaruhi kebersihan gigi dan mulut karena motivasi terjadi akibat timbulnya kepedulian individu dengan suatu hal, yaitu dalam penelitian ini ialah kesehatan gigi dan mulut. ${ }^{17}$

Dari penelitian ini disimpulkan bahwa kepedulian anak untuk berkunjung ke RSGMUnhas tergolong cukup baik berdasarkan tingkat motivasi, tingkat kooperatif,tingkat pengetahuan dan kebersihan gigi dan mulut. Akan tetapi, anak yang berkunjung ke RSGM Unhas masih didominasi oleh pasien yang dijemput oleh operator.

Untuk ituperlupeningkatkan promosi kesehatan yang lebih masif dan program-program yang bertujuan untuk meningkatkan kesadaran masyarakat mengenai kesehatan gigi dan mulut seperti melakukan kerja sama dengan sekolah-sekolah dengan membentuk sekolah binaan dan Usaha Kesehatan Gigi Sekolah.

\section{DAFTAR PUSTAKA}

1. American Academy of Pediatric Dentistry. Policy on the dental home. Pediatir Dent 2015

2. Alhamda S. Status kebersihan gigi dan mulut dengan status karies gigi (kajian pada murid kelompok umur 12 tahun di Sekolah Dasar Negeri Kota Bukittinggi). Berita Kedokteran Masyarakat 2011; 27(2)

3. Basuni C, Putri DKT. Gambaran indeks kebersihan mulut berdasarkan tingkat pendidikan masyarakat di Desa Guntung Ujung Kabupaten Banjar. Jurnal Kedokteran Gigi 2014; II(1)

4. Mawuntu MM, Pangemanan DHC, Mintjelungan C. Gambaran status kebersihan mulut siswa SD Katolik St. Agustinus Kawangkoan. Jurnal e-gigi (eg) 2015; 3(2)

5. Oktarianda B. Hubungan waktu, teknik menggosok gigi dan jenis makanan dengan kejadian karies gigi. 2011

6. WHO. Oral and dental health 2012

7. Maysaroh A, Indriati G, Jumaini. Hubungan tingkat pengetahuan tentang kebersihan gigi dan mulut terhadap perilaku menyikat gigi pada anak usia sekolah di SDN 136 Pekanbaru

8. Pusat Data dan Informasi Kementrian Kesehatan RI. Kondisi capaian Program Kesehatan Anak Indonesia 2014

9. Notoatmodjo S. Metodologi Penelitian Kesehatan. Jakarta : PT Rineka Cipta.

10. Sudjana MA. Metoda Statistika Edisi ke.6. Bandung: Tarsito; 2010

11. Ireland RA Dictionary of dentistry. Oxford: University Press; 2010

12. Alhamda S. Status kebersihan gigi dan mulut dengan status karies gigi. Berita Kedokteran Masyarakat 2011; 27(2)

13. Riyanto A. Aplikasi metodologi penelitian kesehatan. Nuha Medika; 2011

14. Cholil RA, Sukmana BI. Hubungan tingkat pengetahuan kesehatan gigi dan mulut terhadap angka karies gigi di SMPN 1 Marabahan 2016; I(2)

15. Syam AA.Perbedaan tingkat kecemasan dental anak pada kunjungan pertama dan kunjungan berikutnya di RSGMP drg. Hj. Halimah Dg. Sikati FKG Unhas. 2013

16. Kent GG, Blinkhorn AS. Pengelolaan tingkah laku pasien pada praktik dokter gigi. Edisi 2. Alih bahasa: Budiman JA. Jakarta: EGC; 2005.

17. Leininger MM. Caring: an essential human need. Proceedings of three national caring. Michigan: Wayne State University Press; 2003 